\title{
Kinetics Mechanism and Thermodynamic Study of the Oxidation of Iodide Ion by Dichromate Ion in Acidic Medium
}

\author{
${ }^{1}$ NYONG, BE; ${ }^{1 *} \mathrm{ABENG}, \mathrm{FE} ;{ }^{2} \mathrm{USHIE}, \mathrm{OA} ;{ }^{3} \mathrm{BASSEY}, \mathrm{BJ} ;{ }^{1} \mathrm{EDIM}, \mathrm{MM}$ \\ ${ }^{* 5}$ Department of Chemistry, Cross River University of Technology, P. M. B. 1123, Calabar-Nigeria. \\ ${ }^{2}$ Department of Chemical Sciences, Federal University Wukari, Nigeria \\ ${ }^{3}$ Department of Biochemistry, Cross River University, Calabar, Nigeria \\ *Corresponding Author: Email: fidelisabeng@yahoo.com; Tel: +2348035664813
}

\begin{abstract}
This work introduces a newly developed kinetic mechanism and thermodynamic study that gives a clear theoretical insight between the iodine and chromium in acid solution. The paper mainly focuses on evaluating kinetic mechanism and thermodynamic properties of the oxidation of iodide by dichromate ion in acidic medium. This study was investigated using iodometric method. The rate has been studied by appropriate choice of concentrated conditions at constant temperature and ionic strength. The kinetic studies revealed half order reaction with respect to dichromate ion, first order for iodide ion and second order for hydrogen ion concentration. The dependence of reaction rate on the temperature was monitored in order to generate some thermodynamic parameters, which can be used in predicting the direction and spontaneity of the reaction. The thermodynamic studies of this reaction revealed negative values for $\Delta \mathrm{G}, \Delta \mathrm{S}$ and positive values for $\Delta \mathrm{H}$ which is an indication that the reaction was spontaneous and endothermic. The oxidant chromium (vi) exist in acidic media as $\mathrm{H}_{2} \mathrm{CrO}_{4}$. The effect of ionic strength on the rate of redox reaction was investigated. The ionic strength was adjusted by varying the concentration of the nitrate to maximum. The effect of temperature was also studied to evaluate the thermodynamic parameters. Transition metals should be use as catalyst for future purpose to monitor the rate of redox reaction. The techniques employed on this research are very useful in determining the rate of a redox reaction.
\end{abstract}

DOI: $\underline{\text { https://dx.doi.org/10.4314/jasem.v24i5.14 }}$

Copyright: Copyright (C) 2020 Nyong et al. This is an open access article distributed under the Creative Commons Attribution License (CCL), which permits unrestricted use, distribution, and reproduction in any medium, provided the original work is properly cited.

Dates: Received: 16 March 2020; Revised: 11 April 2020; Accepted: 29 April 2020

Keywords: Kinetic, thermodynamic, oxidation, iodometric method

Kinetics provides useful information about the mechanism and rate of chemical reaction, which helps to run a chemical reaction successfully by a way of selecting optimum condition as to get maximum yield. Kinetic study also helps us to Study the factors which influence the rate of reaction like temperature, pressure, substrate concentration, oxidant concentration, composition of reaction mixture and catalyst while Mechanistic study gives a clear theoretical insight between the iodine and chromium (vi) solution in the presence of acid solution, specifically kinetics plays a very important role in the investigation of the reaction of oxidation of iodide compound carried out by oxidizing agent like potassium dichromate (VI) (Fawzy et al., 2014a ; Sayyed et al., 2011). According to the literature survey, considerable amount of work has been done on the oxidation of organic compounds (Sayyed et al., 2011; Fawzy et al., 2014b; Sayyed et al., 2010; Odebunmi et al., 2009; Anweting et al., 2012; Goel, 2010, Khan; Id-Din, 2001) by potassium permanganate, but scanty on the kinetics oxidation of iodide ion by dichromate ion in acidic medium (Ignaz et al., 1997; Isa and kolo, 2015). The objective of this study is to propose kinetic mechanism and evaluate the thermodynamic properties of the oxidation of iodide ion by dichromate ion in acidic medium.

\section{MATERIALS AND METHODS}

All the chemicals used were of AR grade, and were prepared and estimated by standard method. The oxidation of iodide ion by dichromate ion in the acidic medium in was investigated idometrically in the temperature range $10-35^{\circ} \mathrm{C}$ at constant ionic strength of 0.0641 .

Rate Law Determination: Seven burettes were used to dispense the reagents, $50 \mathrm{ml}$ each of trioxonitrate (v) acid solution and Potassium dichromate solution were measured into the first $250 \mathrm{ml}$ beaker. $50 \mathrm{ml}$ each of Potassium iodide and sodium thiosulphate and $10 \mathrm{ml}$ sodium sulphate solution were measured into the second beaker and $15 \mathrm{ml} 2 \%$ starch solution was added. The two $250 \mathrm{ml}$ beakers were placed side by side on the display table and stirring rod was place in the second beaker and quickly the content of the first 
beaker was poured into the second beaker and stirred gently to increase mixing of the two solutions. The time for the reaction was noted from time of mixing to the first appearance of the blue colour.

Temperature of Study: The effect of temperature on the rate of redox reaction was also considered in this study. The same procedure of the previous experiment was employed, except for the variation of temperature which ranges from $10,15,20,25,30$ and $35^{\circ} \mathrm{C}$ This reaction can been represented as equation 1 .

$$
\mathrm{Cr}_{2} \mathrm{O}_{7}{ }^{2-}+6 \mathrm{I}^{-}+14 \mathrm{H}^{+} \rightarrow 2 \mathrm{Cr}^{3+}+3 \mathrm{I}_{2}+7 \mathrm{H}_{2} \mathrm{O} \quad 1
$$

The rate of this reaction can be monitored by the rate of formation of Iodine. Experimental evidence has revealed that as the concentration of reactants increase, the number of molecule or ionic collision increases with a corresponding increase in reaction rate (Isa and kolo, 2015; Atkins and Depaula, 2006) Therefore, the rate of reaction varies with concentration of reactants (raised to some powers) that is

$$
\begin{array}{cc}
\text { Rate }=\left[\mathrm{Cr}_{2} \mathrm{O}_{7}{ }^{2-}\right]^{\mathrm{X}}\left[\mathrm{I}^{-}\right]^{\mathrm{y}}\left[\mathrm{H}^{+}\right]^{\mathrm{Z}} & 2 \\
\frac{d[I 2]}{d t}=\mathrm{k}\left[\mathrm{Cr}_{2} \mathrm{O}_{7}{ }^{2-}\right]^{\mathrm{x}}\left[\mathrm{I}^{-}\right]^{\mathrm{y}}\left[\mathrm{H}^{+}\right]^{\mathrm{z}} & 3 \\
\text { Where } \mathrm{k} \text { is the rate constant. }
\end{array}
$$

\section{RESULTS AND DISCUSSION}

Effect of $\left[\mathrm{Cr}_{2} \mathrm{O}_{7}^{2-}\right]$ on rate of iodine formation: The results of the effect of concentration of each reactant on the rate of Iodine formation are shown on the Figure 1.

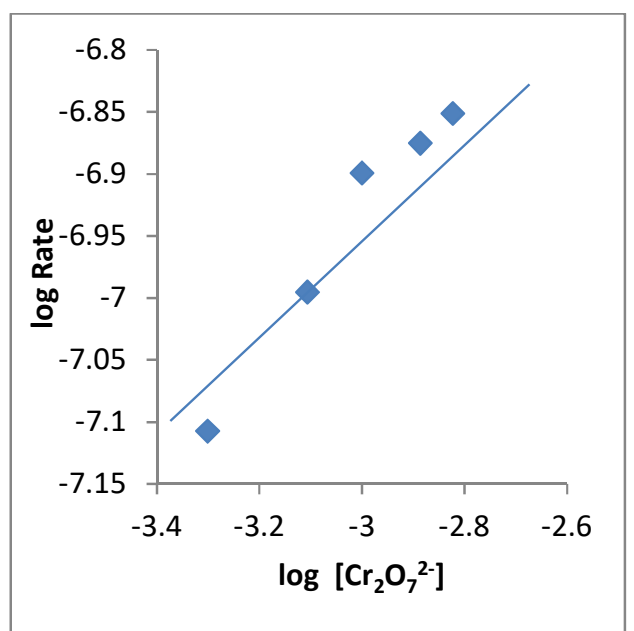

Fig 1. Shows a plot of $\log$ rate against $\log \left[\mathrm{Cr}_{2} \mathrm{O}_{7}{ }^{2-}\right]$

The results shows that the reaction rate increases with increase in the concentration of dichromate ion and the order of reaction was obtained by the linear plot of Figure 1, the plot gave a slope of 0.54 which confirmed half order reaction in dichromate ion concentration
(Atkins and Depaular, 2006). That means the rate of the effect of dichromate ion concentration reaction was increased by half when the concentration of dichromate ion was doubled (Cherkupally and Padma, 2010).

Effect of $\left[\mathrm{I}^{-}\right]$on rate of iodine formation: The result of iodide concentration on the rate of iodine formation has been presented Figure 2. It was also observed from the results that the reaction rate increased as the concentration of iodide ion increases. From the Figure 2 it is observed that linear plot gave a slope of approximately 1 which indicated that the order of reaction with respect to iodine ion was first order reaction (Paricia et al., 2009).

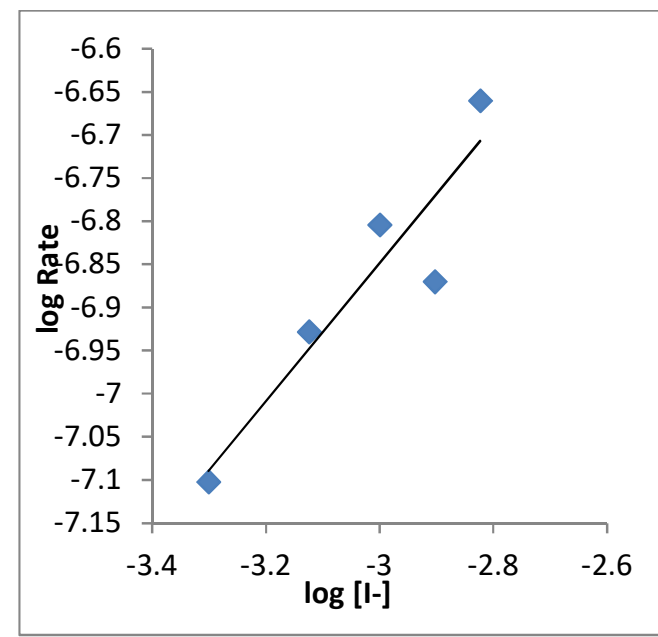

Fig 2. Shows a plot of $\log$ Rate against $\log \left[\mathrm{I}^{-}\right]$

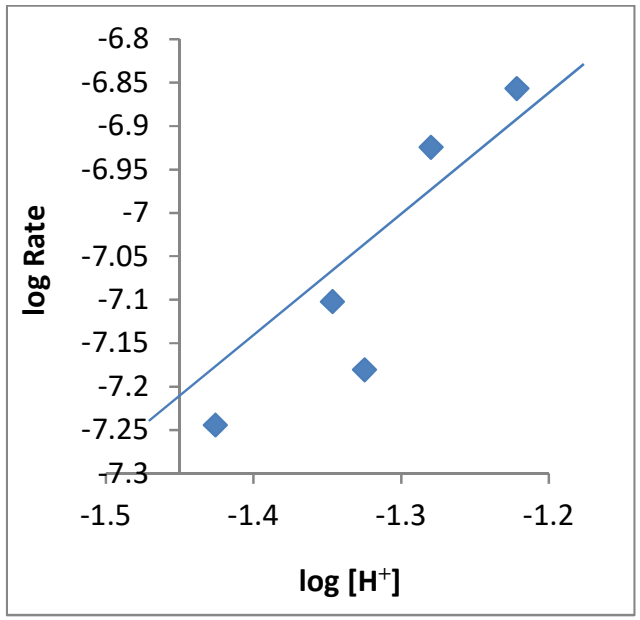

Fig 3. Shows a plot of $\log$ Rate against $\log \left[\mathrm{H}^{+}\right]$

Effect of $\left[\mathrm{H}^{+}\right]$on rate of iodine formation: The dependence of rate of reaction on the concentration of hydrogen ion is display in Figure 3 and it revealed that 
the rate of reaction increases with increased in the acid concentration. The order of reaction with respect to hydrogen ion concentration was obtained from the plot of $\log$ Rate against $\log \left[\mathrm{H}^{+}\right]$shown in Figure 3. The plot was linear and the slope of the plot was 2 confirming second order reactions for hydrogen ion concentration Isa and Kolo, 2015; Sayyed et al., 2010).

Effect of temperature on the rate of redox reaction: The temperature dependence of reaction rates can be studied by plotting a graph between experimental rate constant against the inverse of temperature for different reactions perform. The rate equation for the redox reaction of dichromate and iodide ions in acidic medium is given in equation 4 .

$$
\begin{aligned}
& \frac{d[I 2]}{d t}=\underset{\text { Rate }}{\mathrm{K}\left[\mathrm{Cr}_{2} \mathrm{O}_{7}^{2-}\right]^{1 / 2}\left[\mathrm{H}^{+}\right]\left[\mathrm{I}^{-}\right]} \\
& \mathrm{K}_{\exp }=\frac{\text { Rate }}{[\text { Cr2O7 2- }] 1 / 2[H+][I-]}
\end{aligned}
$$

\begin{tabular}{llllllll}
\multicolumn{7}{c}{ Table 1. Effect of temperature on redox reaction rate } \\
\hline Temp K & $\begin{array}{l}1 / \mathrm{Tx}_{10}^{-3} \\
\mathrm{~K}^{-1}\end{array}$ & $\begin{array}{l}{\left[\mathrm{Cr}_{2} \mathrm{O}_{7}{ }^{2-}\right]} \\
\text { molar }\end{array}$ & $\begin{array}{l}{\left[\mathrm{H}^{+}\right]} \\
\text {molar }\end{array}$ & $\begin{array}{l}{\left[\mathrm{I}^{-}\right]} \\
\text {molar }\end{array}$ & $\begin{array}{l}\text { Rate } \\
\text { molar S }\end{array}$ & $\mathrm{K}_{\exp }$ & $\log \mathrm{K}_{1}$ \\
\hline 283 & 3.53 & 0.001 & 0.045 & 0.0005 & $8.7 \times 10^{-8}$ & 2.71 & 0.434 \\
288 & 3.47 & 0.001 & 0.045 & 0.0005 & $10.2 \times 10^{-8}$ & 3.18 & 0.506 \\
293 & 3.41 & 0.001 & 0.045 & 0.0005 & $11.5 \times 10^{-8}$ & 3.59 & 0.555 \\
298 & 3.35 & 0.001 & 0.045 & 0.0005 & $12.6 \times 10^{-8}$ & 3.94 & 0.595 \\
303 & 3.3 & 0.001 & 0.045 & 0.0005 & $14.3 \times 10^{-8}$ & 4.47 & 0.650 \\
308 & 3.24 & 0.001 & 0.045 & 0.0005 & $16.6 \times 10^{-8}$ & 5.18 & 0.714 \\
\hline
\end{tabular}

The values of the rate constant presented in Table 1 were all evaluated from equation 5 using the data from Table 1. This shows the effect of temperature on the experimental rate constant. The results illustrated that the experimental rate constant, $\mathrm{k}_{\exp }$ increases as the temperature increases (Eddy et al., 2018, Atkins and Depaula, 2006).

$$
\log K \exp =\log A-\frac{E a}{2.30 \text { RT }} \quad 6
$$

According equation 6 , the Plot of $\log \mathrm{k}_{\exp }$ versus the reciprocal of temperature $1 / \mathrm{T}$ gave linear plot of slope -0.926 illustrated in Figure 4. The activation energy was calculated Using equation 7 .

$$
\text { Slope }=-\frac{E a}{2.30 \mathbb{R}} \quad 7
$$

The calculated activation energy was given as $17.7 \mathrm{kjmol}^{-1}$ or $4.71 \mathrm{kcalmol}^{-1}$ while the pre-exponential factor A was calculated as 3.709 .

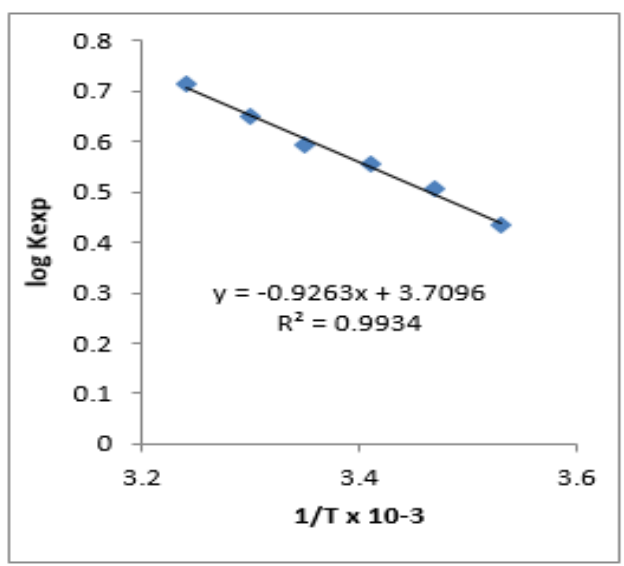

Fig 4. Plot of $\log \mathrm{K}_{\exp }$ against $1 / / \mathrm{T}$
Effect of Ionic Strength on the Rate of Redox Reaction: The effect of ionic strength on the rate of redox reaction was investigated; the ionic strength was adjusted by varying the concentration of the

\begin{tabular}{|c|c|c|c|c|}
\hline \multirow[t]{2}{*}{ Run } & \multirow[t]{2}{*}{ I } & Rate K & \multicolumn{2}{|l|}{$\log K$} \\
\hline & & Molar S ${ }^{-1}$ & & $\sqrt{I}$ \\
\hline 1 & 0.0564 & $12 \times 10^{-8}$ & 0.5812 & 0.2375 \\
\hline 2 & 0.0617 & $11.7 \times 10^{-8}$ & 0.5589 & 0.2484 \\
\hline 3 & 0.0647 & $11.5 \times 10^{-8}$ & 0.5517 & 0.2544 \\
\hline 4 & 0.0665 & $11.1 \times 10^{-8}$ & 0.5363 & 0.2579 \\
\hline 5 & 0.0689 & $10.8 \times 10^{-8}$ & 0.5322 & 0.2625 \\
\hline
\end{tabular}
dichromate ion, hydrogen ion and iodide to maximum. Since increase in concentration of a reactant increases ionic strength.

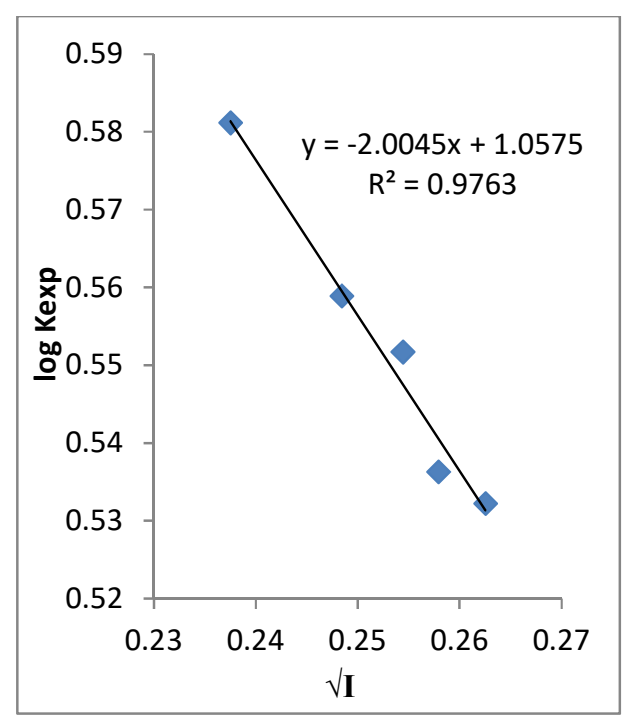

Fig 5. Showing Plot of $\log \mathrm{k}_{\text {exp }}$ versus $\sqrt{I}$ 
The results listed in Table 2 revealed that the reaction rate constant decreases with increase in ionic strength. The corresponding values of the experimental rate constants were evaluated from equation 5, then logarithm of experimental rate $\operatorname{logk}_{\mathrm{exp}}$ was plotted against the square root of total ionic strength $\sqrt{I}$ with slope of -2.004 shown in Figure5 (Khalid, 2007).

$$
\mathrm{A}+\mathrm{B} \rightarrow \text { Products }
$$

$Z_{A} Z_{B}=-2$ represent equation 8 .

Ionic species for dichromate ion $\mathrm{Cr}_{2} \mathrm{O}_{7}{ }^{2}$ is represented as $\mathrm{A}$ with charge of -2 and $\mathrm{B}$ represent ionic ionic species of acid $\mathrm{H}^{+}$with a charge of +1 . Therefore primary elementary step of this species are illustrated in equation 7-8.

$$
\begin{aligned}
& \mathrm{A}^{2-}+\mathrm{B}^{+} \rightarrow \text { Intermediate } \rightarrow \text { Products } \\
& \mathrm{Cr}_{2} \mathrm{O}_{7}{ }^{2-}+\mathrm{H}_{2} \mathrm{O} \stackrel{\mathrm{H}+}{\Leftrightarrow} \mathrm{HCrO}_{4}^{-}
\end{aligned}
$$

The possible explanation for $Z_{A} Z_{B}$ is -2 for equation 7 and the primary elementary step show the protonation of dichromate ion followed by the addition of $\mathrm{OH}^{-}$to form $2 \mathrm{HCrO}_{4}$.

Thermodynamic Consideration: Thermodynamic parameters are unique in predicting the direction and spontaneity of a reaction. The cardinal equation in estimating the standard changes in free energy $\Delta \mathrm{G}$, enthalpy $\Delta \mathrm{H}$, and entropy $\Delta \mathrm{S}$ is state in equation 11 and 12.

$$
\begin{aligned}
& \Delta G=-2.303 R T \log K \exp \\
& \log \mathrm{Kexp}=\frac{R}{N R}-\frac{\Delta H}{R T}
\end{aligned}
$$

Where $\mathrm{N}$ is the Avogadro's number, $\mathrm{h}$ is the plank constant, $\Delta \mathrm{H}$ is the enthalpy of the reactions, $\mathrm{R}$ is the gas constant and $\mathrm{T}$ is the absolute temperature. The application of transition state equation to redox reaction of iodide was confirmed by the high degree of linearity displayed by the plot of $\log$ Kexp versus $1 / T$ as shown in Figure 4. Table 2 contains values of $\Delta H$ that were calculated from the slope of Figure 4, Using equation 13

$$
\text { slope }=-\frac{\Delta H}{R}
$$

IWhile the entropy was evaluated by equation 14 .

$$
\Delta S=\Delta G-\Delta H
$$

It is seen from the listed results that change in enthalpy is generally positive. Predicting the reaction to be endothermic. Negative values obtained for change in

\begin{tabular}{|c|c|c|c|c|c|c|}
\hline \multicolumn{3}{|c|}{ Effect of Ionic strength } & \multicolumn{4}{|c|}{ Effect of Temperature } \\
\hline $\begin{array}{l}\text { Temp } \\
\mathrm{K}\end{array}$ & $\begin{array}{l}\log \\
\mathrm{k}\end{array}$ & $\begin{array}{l}\Delta \mathrm{G} \\
\mathrm{kJmol}^{-1}\end{array}$ & $\log \mathrm{k}$ & $\begin{array}{l}\Delta \mathrm{G} \\
\mathrm{kJmol}^{-1}\end{array}$ & $\begin{array}{l}\Delta \mathrm{H} \\
\mathrm{kJmol}^{-1}\end{array}$ & $\begin{array}{l}\Delta \mathrm{S} \\
\mathrm{kJmol}^{-1}\end{array}$ \\
\hline 283 & 0.5812 & -3.14 & 0.434 & -2.35 & 2.17 & -4.52 \\
\hline 288 & 0.5589 & -3.08 & 0.506 & -2.79 & 2.21 & -5.00 \\
\hline 293 & 0.5517 & -3.09 & 0.555 & -3.11 & 2.25 & -5.36 \\
\hline 298 & 0.5363 & -3.06 & 0.595 & -3.39 & 2.29 & -5.68 \\
\hline 303 & 0.5322 & -3.08 & 0.65 & -3.77 & 2.33 & -6.10 \\
\hline 308 & 0.5134 & -3.03 & 0.714 & -4.21 & 2.37 & -6.58 \\
\hline
\end{tabular}
entropy confirm that there is association of the reaction between the iodide and chromate in acidic media, while free energy of reaction shows that the reaction was spontaneous (Eddy et al., 2018; Ikpi et al., 2017; Abeng et al., 2017).

Table 3. Thermodynamic parameters

Mechanism on the rate of redox reaction: Based on the experimental results obtained and the Stoichiometry of the reaction, the following reaction mechanisms were proposed for this study.

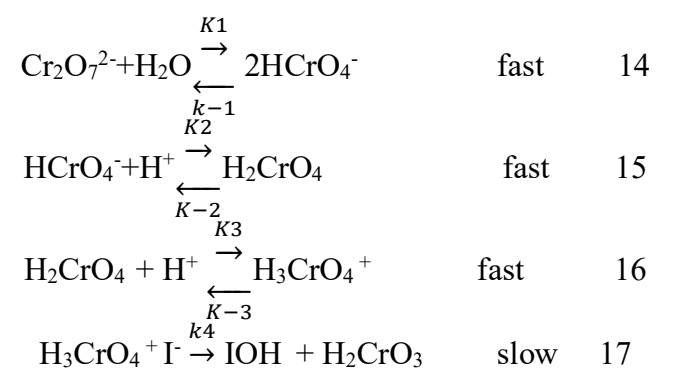

$$
\begin{array}{lll}
\mathrm{IOH}+\mathrm{I}^{-}+\mathrm{H}^{+} \stackrel{K 5}{\rightarrow} \mathrm{I}_{2}+\mathrm{H}_{2} \mathrm{O} & \text { Fast } & 18 \\
\text { Rate }\left(\mathrm{I}_{2}\right)=\mathrm{K} 4\left[\mathrm{H}_{3} \mathrm{CrO}_{4}^{+}\right]\left[\mathrm{I}^{-}\right] & \text {Fast } & 19
\end{array}
$$

Appling steady state approximation to the reactive intermediates of equation 16 to yield equation 20

$$
0=\mathrm{K}_{3}\left[\mathrm{H}_{2} \mathrm{CrO}_{4}\right]\left[\mathrm{H}^{+}\right]-\mathrm{K}_{-3}\left[\mathrm{H}_{3} \mathrm{CrO}_{4}^{+}\right] 20
$$$$
\mathrm{K}_{-3}\left[\mathrm{H}_{3} \mathrm{CrO}_{4}^{+}\right]=\mathrm{K}_{3}\left[\mathrm{H}_{2} \mathrm{CrO}_{4}\right]\left[\mathrm{H}^{+}\right]
$$ 


$$
\left[\mathrm{H}_{3} \mathrm{CrO}_{4}^{+}\right]=\frac{K 3}{K-3}\left[\mathrm{H}_{2} \mathrm{CrO}_{4}\right]\left[\mathrm{H}^{+}\right] \quad 22
$$

Substituting equation 22 into equation 19 yield equation 23

$$
\text { Rate }\left(\mathrm{I}_{2}\right)=\mathrm{K} 4 \frac{K 3}{K-3}\left[\mathrm{H}_{2} \mathrm{CrO}_{4}\right]\left[\mathrm{H}^{+}\right]\left[\mathrm{I}^{-}\right] \quad 23
$$

In considering equation 15

$$
\begin{gathered}
0=\mathrm{K}_{2}\left[\mathrm{HCrO}_{4}^{-}\right]\left[\mathrm{H}^{+}\right]-\mathrm{K}_{-2}\left[\mathrm{H}_{2} \mathrm{CrO}_{4}\right] \\
\mathrm{K}_{-2}\left[\mathrm{H}_{2} \mathrm{CrO}_{4}\right]=\mathrm{K}_{2}\left[\mathrm{HCrO}_{4}^{-}\right]\left[\mathrm{H}^{+}\right] \quad 25 \\
{\left[\mathrm{H}_{2} \mathrm{CrO}_{4}\right]=\frac{K 2}{K-2}\left[\mathrm{H}_{2} \mathrm{CrO}_{4}^{-}\right]\left[\mathrm{H}^{+}\right]}
\end{gathered}
$$

Substitute for $\left[\mathrm{H}_{2} \mathrm{CrO}_{4}\right]$ in equation 23 we have equation 27

$$
\text { Rate }\left(\mathrm{I}_{2}\right)=\mathrm{K}_{4} \frac{K 3 K 2}{K-3 K-2}\left[\mathrm{HCrO}_{4}{ }^{-}\right]\left[\mathrm{H}^{+}\right]\left[\mathrm{I}^{-}\right] \quad 27
$$

Applying steady state approximation also to equation 14 we have equation 28

$$
\begin{aligned}
& 0=\mathrm{K}_{1}\left[\mathrm{Cr}_{2} \mathrm{O}_{7^{2}}^{2-}\right]\left[\mathrm{H}_{2} \mathrm{O}\right]-\mathrm{K}_{-1}\left[\mathrm{HCrO}_{4}^{-}\right]^{2} 28 \\
& {\left[\mathrm{HCrO}_{4}\right]^{-2}=\frac{K 1}{K-1}\left[\mathrm{Cr}_{2} \mathrm{O}_{7}^{2-}\right]\left[\mathrm{H}_{2} \mathrm{O}\right] \quad 29}
\end{aligned}
$$

Therefore

$$
\left.\left[\mathrm{HCrO}_{4}^{-}\right]=\left[\frac{K 1}{K-1}\right]\right]^{1 / 2}\left[\mathrm{Cr}_{2} \mathrm{O}_{7}^{2-}\right]^{1 / 2} \quad 30
$$

In Substituting equation 30 into equation 27 we obtained equation 31

$$
\text { Rate }\left(\mathrm{I}_{2}\right)=\mathrm{K}_{4} \frac{K 3 K 2}{K-3 K-2}\left[\frac{K 1}{K-1}\right]^{1 / 2}\left[\mathrm{Cr}_{2} \mathrm{O}_{7}^{2-}\right]^{1 / 2}\left[\mathrm{H}^{+}\right]^{2}\left[\mathrm{I}^{-}\right]
$$

Therefore equation 31 can further be express as follows:

$$
\begin{aligned}
& \text { Rate }\left(\mathrm{I}_{2}\right)=\mathrm{Kexp}\left[\mathrm{Cr}_{2} \mathrm{O}_{\left.7^{2-}\right]^{1 / 2}\left[\mathrm{H}^{+}\right]^{2}\left[\mathrm{I}^{-}\right]} 32\right. \\
& \mathrm{Kexp}=\mathrm{K}_{4} \mathrm{~K}
\end{aligned}
$$

Where $\mathrm{K}$ is equation 33

$$
\mathrm{K}=\frac{K 3 K 2}{K-3 K-2}\left[\frac{K 1}{K 1}\right]^{1 / 2}
$$

Arrhenius form of equation 34 is express as equation 35 .

$$
\underset{\mathrm{KK} 4=\mathrm{Ae}-{ }^{\mathrm{Ea} / \mathrm{RT}}}{\mathrm{K} \exp }=\mathrm{A} e^{-\mathrm{Ea} / \mathrm{RT}}=\mathrm{K}_{4} \mathrm{~K}
$$

Thus equation 35 was used in plotting graph of Rate of reaction versus the inverse of temperature to determine the activation energy of the redox reaction for the formation of iodine by dichromate ion. The above equation from 14 to 34 provides the mechanistic process of the redox reactions (Atkins and Depaula, 2006)

Conclusions: The reaction between iodine and chromium (vi) was investigated in trioxonitrate (v) acid. The oxidant chromium (vi) exist in acidic media as $\mathrm{H}_{2} \mathrm{CrO}_{4}$ which takes part in the chemical reaction. The propose mechanism for the reaction confirm the kinetic studies of redox reaction with half order reaction for dichromate ion, first order for iodide ion and second order for hydrogen ion concentration. The effect of ionic strength on the rate of redox reaction was investigated. The ionic strength was adjusted by varying the concentration of the nitrate to maximum. The effect of temperature was also studied to evaluate the thermodynamic parameters.

\section{REFERENCES}

Abeng, F E; Idim, V D; Nna, PJ (2017). Kinetic and thermodynamic studies of corrosion inhibition of mild steel using methanolic extract of Erigeron floribundus (Kunth) in $2 \mathrm{M} \mathrm{HCl}$ solution. W. News Nat. Sci. 10 (2017): 26-38.

Anweting, I B; Iyun, J F; Idus, SO (2012). Kinetics and mechanistic approach to the oxidation of Ltryptophan by permanganates ion in aqueous acidic medium. Adv. Appl. Sci. Res.3 (2012):3401 -3409 .

Atkin, P; Depaula, J; (2006), Physical Chemistry eight edition, Oxford University.

Cherkupally, S R; Padma, S M (2010). Kinetics and mechanism of Acid Bromate Oxidation of Substituted 4-oxoacids. Indian J. of Chem. 49(2010): 418-424.

Eddy, NO; Ameh, PO; Essien, NO (2018). Experimental and computational chemistry studies on the inhibition of aluminium and mild steel in $0.1 \mathrm{M} \mathrm{HCl}$ by 3-nitrobenzene acid. Tai. Univ. Sci. 12 (5): 545-556.

Fawzy, A; Ashour, S S; Musleh, M A (2014a). Base catalyzed oxidation of L-asparagius by alkaline permanganate ions in sulpuric acid medium, Int. J. Chem Kinet. 46(2014): 370 - 381.

Fawzy, A; Ashour, S S; Musleh, M A; Hassan, R M; Asghar, B H (2014b). Kinectics and mechanism approach to the chromic acid oxidation of Ltryptophan with a spectral detection of Chromium (III) product. J. Saudi Chem. Soc. http://dx.doi.org/10.1016/J.JSCS.2014.10.003 
Goel, A; Sharma, S (2010). Mechanistic study of the oxidation of Phenylalanine by hexacynoferrate (III) catalyzed by Iridium in aqueous alkaline medium. Trans. metal chem. 35 (2010): 549 554.

Iguaz, J B; Stephen, J H (1997). Kinetics and pH dependence of Chromium (vi) reduction by Iron (II). Env. Sci. Tech. 31(1997):1426-1432.

Ikpi, M E; Abeng, F E; Obono O E (2017).Adsorption and Thermodynamic studies for the corrosion of inhibition of API 5L X-52 Steel in $2 \mathrm{M} \mathrm{HCl}$ solution bymoxifloxacin. $W$. news nat. sci. 9(2017): 79-90.

Isa, BK; Kolo, AM (2015). The kinetics of oxidation of iodide ion by Dechromate ion in an Acidic medium. Int. J. Adv. Chem. Res. 4, (10): $44-48$.

Khan, Z; Id-Din, K (2001). Effect of Manganso (II) ions on the oxidation of Maleic and Oxaloethanoic acids by aqueous $\mathrm{H} 2 \mathrm{Cr}$ O4. Trans. Metal Chem. 26 (2001): $672-678$.
Khalid, MA (2007). Oxidative kinetic of amino acids by peroxydisulphate effect of dielectric constant. Arab. J. Sci. Eng. 33(2007):199-210.

Odebunmi, E O; Obike, AI; Owalude S O (2009). Kinetic and mechanism of oxidation of D-xylose and L-arabinose by Chromium (VI) ions in per chloric acid medium. Int. J. Bio. Chem. 3(2009): $178-185$.

Patricia, MF; James, A O; George, W. L. (2009). The kinetics of iodide oxidation by manganese oxide. Geo. chem. chim. Acta. 73 (10): 2850-2861.

Sayyed, H S; Mazhar, F N; Gaikwad, D O (2010). Kinetic and mechanistic study of oxidation of ester by $\mathrm{KMnO}_{4}$ Int. J. Chem. Res. 2(1): $242-$ 249.

Sayyed, H S; Gour, S R; Mazhar, F N (2011). Kinetic and mechanistic study of oxidation of ester by $\mathrm{K}_{2}$ $\mathrm{Cr}_{2} \mathrm{O}_{7}$. Der Chem. Sinica. 2(1):61 - 65 . 